\title{
Determinants of dietary supplement use - healthy individuals use dietary supplements
}

\author{
Christina L. F. Kofoed ${ }^{1}$, Jane Christensen ${ }^{1}$, Lars O. Dragsted ${ }^{2}$, Anne Tjønneland ${ }^{1}$ and Nina Roswall ${ }^{1 *}$ \\ ${ }^{1}$ Danish Cancer Research Center, Danish Cancer Society, Strandboulevarden 49, DK-2100 Copenhagen Ø, Denmark \\ ${ }^{2}$ Department of Nutrition, Exercise and Sports, Faculty of Life Science, University of Copenhagen, \\ Nørre Allé 51, DK-2200 Copenhagen N, Denmark
}

(Submitted 19 December 2014 - Final revision received 3 March 2015 - Accepted 1 April 2015 - First published online 5 May 2015)

\section{Abstract}

The prevalence of dietary supplement use varies largely among populations, and previous studies have indicated that it is high in the Danish population compared with other European countries. The diversity in supplement use across countries indicates that cultural and environmental factors could influence the use of dietary supplements. Only few studies investigating the use of dietary supplements have been conducted in the Danish population. The present cross-sectional study is based on 54948 Danes, aged 50-64 years, who completed self-administrated questionnaires on diet, dietary supplements and lifestyle between 1993 and 1997. A health index including smoking, physical activity, alcohol and diet, and a metabolic risk index including waist circumference, urinary glucose and measured hypertension were constructed. Logistic regression was used to investigate these determinants in relation to the intake of dietary supplements. We found that $71 \%$ of the participants were dietary supplement users; female sex, older age groups and higher educated participants were more likely to be users of any dietary supplements. One additional point in the health index was associated with 19, 16 and $9 \%$ higher likelihood of being user of any, more common and less common supplements, respectively. In the metabolic risk index, one additional point was associated with 17 and 16\% lower likelihood of being user of any supplement and more common supplements, respectively. No significant association was found for less common supplement use. In conclusion, those with the healthiest lifestyle were more likely to use dietary supplements. Thus, lifestyle and dietary composition should be considered as confounders on supplement use and health outcomes.

\section{Key words: Dietary supplements: Determinants: Health status: Epidemiology}

Previous studies on determinants of dietary supplements have indicated that people who use dietary supplements are generally more health-conscious than non-users, with regard to both dietary choices ${ }^{(1-3)}$, as well as general lifestyle ${ }^{(2)}$. Female $\operatorname{sex}^{(1,4-7)}$, older age ${ }^{(1,5,8-11)}$ and higher education ${ }^{(1,5-7)}$ have previously been found to be associated with dietary supplement use. The prevalence of dietary supplement use varies considerably among populations, and previous studies have indicated that it is high in the Danish population compared with other European countries ${ }^{(11-13)}$. The diversity in supplement use across countries indicates that cultural and environmental factors could influence the use of dietary supplements.

Only few studies investigating the use of dietary supplements have been conducted in the Danish population. Tetens et al. ${ }^{(11)}$ found that the use of dietary supplements is higher among women than among men and increases with age, and the intention to eat healthy. Knudsen et al. ${ }^{(12)}$ concluded that the use of dietary supplements is positively related to age and former smoking, but also to poor self-perceived health status. These studies investigated only few determinants, and many more aspects, such as diet intake, physical activity and metabolic risk factors, need to be investigated. Furthermore, the determinants for different kinds of supplements have not been investigated. These previous studies have suggested that also in the highly supplement-using Danish population, users tend to be more health-conscious than non-users. However, a more detailed insight into the determinants for supplement use is needed in the Danish population, especially in relation to health behaviours and health status.

The Diet, Cancer and Health cohort includes 57053 Danes, aged 50-64 years at baseline, who gave detailed information on both dietary supplement use and lifestyle, and it, thus, has the statistical power to explore several determinants for dietary supplement use for a broad range of supplements. The objective of the present study was to investigate the determinants for the use of dietary supplements in relation to subject characteristics, a health index and a metabolic risk index in middle-aged men and women participating in the Diet, Cancer and Health cohort. This was done in order to understand the behavioural characteristics

*Corresponding author: N. Roswall, fax +45 352577 31, email roswall@cancer.dk 
of supplement use in the Danish population in relation to health and disease risk.

\section{Methods}

\section{Study population}

The present cross-sectional study was based on the data from the prospective Danish cohort 'Diet, Cancer and Health' in which 160725 Danes were invited to participate. During the period 1993-7, a total of 57053 men and women $(35 \%$ of those invited) residing in the greater Copenhagen or Aarhus area accepted the invitation. The inclusion criteria were age between 50-64 years, born in Denmark and no previous cancer diagnosis registered in the Danish Cancer Registry ${ }^{(14)}$. The study was approved by the regional ethical committees of human studies in Copenhagen and Aarhus and by the Danish Data Protection Agency.

\section{Exclusion criteria}

Participants were excluded if they have had a cancer diagnosis at the time of enrolment ( $n 574$ ), if information on one or more variables of interest was lacking ( $n$ 1512) and if conflicting answers (e.g. no use of supplements in the previous years and use of multivitamin supplement in the previous year) were given regarding the intake of dietary supplements ( $n$ 19). In total, 54948 men and women were included in the present analyses.

\section{Dietary supplements}

In the FFQ distributed at study baseline (1993-7), the use of dietary supplements was assessed by open-ended questions on brands and doses and categorical questions on consumption frequency.

All types of dietary supplements were grouped according to their main content, so that in supplements with more than one component (e.g. Ca + vitamin D), the primary component of the supplement determined the allocation (in this case: $\mathrm{Ca}$ ). This was done as it was assumed that the intention to use a supplement was due to its primary component. The different types of supplements were divided into more common or less common supplements. The more common supplements are mainly vitamins and minerals and include multivitamins, multiminerals, vitamin $\mathrm{B}$, antioxidant vitamins, $\mathrm{Ca}, \mathrm{Fe}, n-3$ fatty acids (fish oil), vitamin $\mathrm{D}, \mathrm{Zn}, \mathrm{Mg}, \mathrm{Cr}, \mathrm{I}, \mathrm{Cu}, \mathrm{Mn}, \mathrm{K}$ and Si. Less common dietary supplements are all other supplements, but mainly herbal extracts and include ginseng, gingko biloba, garlic, royal jelly, wheat germ, $\boldsymbol{\gamma}$-linolenic acid, ginger, chlorophyll, algae, gut regulating supplements (mainly insoluble fibres), brewer's yeast, baldrian, guarmin, lecithin, propolis and any additional dietary supplements. The term 'any dietary supplement' includes both more common and less common dietary supplements. In the present study, the three groups, any, more common and less common dietary supplements, are used for the data analyses. In addition, results for the following subgroups of supplements were also investigated: multivitamins; multiminerals; antioxidants; vitamin $\mathrm{B}$; $\mathrm{Ca}$; Fe; fish oil; ginseng; gingko biloba; wheat germ; garlic; royal jelly.

A dietary supplement user was defined as a person who reported taking at least one dietary supplement during the past 12 months before filling the FFQ.

\section{Data collection}

Diet was assessed through a validated semi-quantitative 192-item FFQ mailed to each participant, which considered food intake in the past 12 months ${ }^{(15)}$. Additionally, each participant visited the study centre and filled in a lifestyle questionnaire including information on physical activity, smoking habits and alcohol consumption. The questionnaire was checked for missing information by optical scanning during the visit so that errors could be checked with participants, preferably before leaving the study centre. The software program FoodCalc ${ }^{(16)}$, specifically developed with standardised recipes and portion sizes integrated, was used to calculate the daily intake of specific food and nutrients by each participant.

\section{Health index and metabolic risk index}

Two indexes were constructed to identify the potential determinants of supplement use. A health index was generated from dietary and lifestyle variables which included information on smoking habits, physical activity, alcohol consumption and dietary factors (Table 1). All the four factors count equally with a score of 0 or 1 to the overall health index, which has been slightly modified from an existing index ${ }^{(17)}$. The index was constructed

Table 1. The health index - factors included, categorisation and score assignment

\begin{tabular}{|c|c|c|}
\hline Factors & Categorisation of the participants & Point \\
\hline \multirow[t]{2}{*}{ Smoking } & Smokers & 0 \\
\hline & Non-smokers & 1 \\
\hline \multirow[t]{2}{*}{ Physical activity } & $<4 \mathrm{~h}$ of physical activity/week & 0 \\
\hline & $\geq 4 \mathrm{~h}$ of physical activity/week & 1 \\
\hline \multirow[t]{2}{*}{ Alcohol consumption } & $>14$ (women)/21 (men) units/week & 0 \\
\hline & $\leq 14$ (women)/21 (men) units/week & 1 \\
\hline \multirow[t]{12}{*}{ Diet } & Dietary sub-index: & \\
\hline & 0 point for each of the following & \\
\hline & $\begin{array}{l}<30 \mathrm{~g} \text { of } \mathrm{fish} / \mathrm{d} \\
<400 \mathrm{~g} \text { of fruit and vegetables/d }\end{array}$ & \\
\hline & $<39 \mathrm{~g}^{\star}$ of whole grain/d & \\
\hline & $\begin{array}{l}>743 \mathrm{~g} \dagger \text { of red and processed } \\
\text { meat/week }\end{array}$ & \\
\hline & Dietary sub-index: & \\
\hline & $\begin{aligned} & 1 \text { point for each of the following } \\
\geq & 30 \mathrm{~g} \text { of } \mathrm{fish} / \mathrm{d}\end{aligned}$ & \\
\hline & $\geq 400 \mathrm{~g}$ of fruit and vegetables/d & \\
\hline & $\geq 39 \mathrm{~g}^{\star}$ of whole grain/d & \\
\hline & $\begin{aligned} \leq 743 \mathrm{~g} \dagger \text { of red and processed } \\
\text { meat/week }\end{aligned}$ & \\
\hline & $\begin{array}{l}\text { A total of }<2 \text { points in the dietary } \\
\text { sub-index }\end{array}$ & 0 \\
\hline & $\begin{array}{l}\text { A total of } \geq 2 \text { points in the dietary } \\
\text { sub-index }\end{array}$ & 1 \\
\hline Health index & Score ranging from & $0-4$ \\
\hline
\end{tabular}

${ }^{*}$ Median of whole grain intake $(\mathrm{g} / \mathrm{d})$.

$\dagger$ Median of red and processed meat ( $\mathrm{g} /$ week). 
Table 2. The metabolic risk index - factors included, categorisation and score assignment

\begin{tabular}{llc}
\hline Factors & Categorisation of the participants & Point \\
\hline Waist circumference & $\leq 88 \mathrm{~cm}$ (women) $/ 102 \mathrm{~cm}$ (men) & 0 \\
& $>88 \mathrm{~cm}$ (women) $/ 102 \mathrm{~cm}$ (men) & 1 \\
Hypertension & No & 0 \\
& Yes $(\geq 140 \mathrm{mmHg}$ systolic & 1 \\
Urine glucose test & and $/$ or $\geq 90 \mathrm{mmHg}$ diastolic) & \\
Megative & 1 \\
& Positive & $0-3$ \\
\hline
\end{tabular}

in accordance with the Danish dietary and lifestyle recommendations from the same period as the recruitment of participants occurred. The index was dichotomised for each factor in relation to the recommendations or the median intake; if participants followed the recommendations, or were above the median, one point was assigned.

In order to weigh the dietary factors into the health index, a sub-index was constructed with four categories (intake of fish, fruit/vegetables, whole grain and red/processed meat), where $0-1$ points in this sub-index resulted in zero point in the health index, and $2-4$ points in the sub-index resulted in one point in the health index. The median was used as a cut-point for the intake of whole grain and red/processed meat, due to the fact that no recommendations were given in the applied guideline.

We did not have access to all variables that are necessary to produce a metabolic syndrome score. As a proxy, our metabolic risk index includes three variables: waist circumference; measured blood pressure; urine glucose test. The index was dichotomised for each factor. One point was assigned for waist circumference above the recommended (women: $>88 \mathrm{~cm}$, men: $102 \mathrm{~cm}$ ), one point for measured hypertension ( $\geq 140 \mathrm{mmHg}$ systolic and/or $\geq 90 \mathrm{mmHg}$ diastolic) and one point for a positive urine glucose test (positive). The metabolic risk index is presented in Table 2 . It is important to note that the health index is constructed to be directly related to health status while the metabolic risk index by design is inversely related to health.

\section{Statistical analysis}

Descriptive characteristics were given by percentages of all included participants and all dietary supplement users. Proportion of dietary supplement users and types of dietary supplements used were described.

The OR and 95\% CI were calculated using logistic regression analyses comparing supplement users (those who reported the use of supplements in the past 12 months) and non-users regarding sex, age (50-54, 55-59 and 60-64 years) and education (low, middle and high), scores in the health index and scores in the metabolic risk index. All these factors were mutually adjusted in the adjusted model.

Linearity was tested for age; however, the assumption of linearity was not met, and thus age was included as a categorical variable.
All analyses were carried out using SAS (version 9.3, SAS Institute, Inc.) on a Windows platform. In the logistic regression analyses, the PROC GENMOD procedure was applied.

\section{Results}

In total, $52 \%$ of the participants were women, and nearly half of the participants had educations of median length, and were aged between 50 and 54 years (Table 3). The majority of the participants scored two or three points in the health index. For the metabolic risk index, the major part scored zero or one points.

\section{Dietary supplement use}

More than $71 \%$ of the population used at least one dietary supplement during the past 12 months (Table 4). A greater percentage of women than men reported dietary supplement use (78v. 63\%, $P$ for difference from $\chi^{2}=<0.0001$ ). Of the supplement users, 64, 38 and 24\%, respectively, recorded taking multivitamin, antioxidant and fish oil supplements during the past 12 months. These supplements were the most commonly used supplements for both men and women.

\section{Demographic factors}

The OR for using any dietary supplements was 1.95 (95\% CI $1.88,2.03$ ) for women compared with men, and the same significant differences were found for the use of more

Table 3. Characteristics of all the participants and dietary supplement users for demographic factors, health index and metabolic risk index

(Number of participants and percentages)

\begin{tabular}{|c|c|c|c|c|c|c|}
\hline & \multicolumn{2}{|c|}{$\begin{array}{c}\text { All } \\
\text { participants }\end{array}$} & \multicolumn{2}{|c|}{$\begin{array}{c}\text { Users of } \\
\text { dietary } \\
\text { supplements }\end{array}$} & \multicolumn{2}{|c|}{$\begin{array}{c}\text { Non-users of } \\
\text { dietary } \\
\text { supplements }\end{array}$} \\
\hline & $n$ & $\%$ & $n$ & $\%$ & $n$ & $\%$ \\
\hline \multicolumn{7}{|l|}{ Sex } \\
\hline Male & 26181 & $47 \cdot 7$ & 16572 & $42 \cdot 4$ & 9609 & $60 \cdot 6$ \\
\hline Female & 28767 & $52 \cdot 3$ & 22527 & $57 \cdot 6$ & 6240 & 39.4 \\
\hline \multicolumn{7}{|c|}{ Age (years) } \\
\hline $50-54$ & 23221 & $42 \cdot 3$ & 15802 & $40 \cdot 4$ & 7419 & $46 \cdot 8$ \\
\hline $55-59$ & 17042 & $31 \cdot 0$ & 12334 & $31 \cdot 6$ & 4708 & 29.7 \\
\hline $60-64$ & 14685 & $26 \cdot 7$ & 10963 & $28 \cdot 0$ & 3722 & 23.5 \\
\hline \multicolumn{7}{|l|}{ Education } \\
\hline Low & 18048 & 32.9 & 11969 & $30 \cdot 6$ & 6079 & 38.4 \\
\hline Middle & 25345 & $46 \cdot 1$ & 18479 & $47 \cdot 3$ & 6866 & $43 \cdot 3$ \\
\hline High & 11555 & $21 \cdot 0$ & 8651 & $22 \cdot 1$ & 2904 & $18 \cdot 3$ \\
\hline \multicolumn{7}{|c|}{ Health index } \\
\hline 0 & 1863 & 3.4 & 1055 & $2 \cdot 7$ & 808 & $5 \cdot 1$ \\
\hline 1 & 8158 & 14.9 & 5109 & $13 \cdot 1$ & 3049 & $19 \cdot 2$ \\
\hline 2 & 16611 & $30 \cdot 2$ & 11583 & $29 \cdot 6$ & 5020 & $31 \cdot 7$ \\
\hline 3 & 19617 & 35.7 & 14602 & $37 \cdot 3$ & 5015 & 31.6 \\
\hline 4 & 8699 & $15 \cdot 8$ & 6750 & $17 \cdot 3$ & 1949 & $12 \cdot 3$ \\
\hline \multicolumn{7}{|c|}{ Metabolic risk index } \\
\hline 0 & 22629 & $41 \cdot 2$ & 16782 & $42 \cdot 9$ & 5847 & 36.9 \\
\hline 1 & 23306 & $42 \cdot 4$ & 16511 & $42 \cdot 2$ & 6795 & 42.9 \\
\hline 2 & 8660 & $15 \cdot 8$ & 5613 & $14 \cdot 4$ & 3047 & $19 \cdot 2$ \\
\hline 3 & 353 & 0.6 & 193 & 0.5 & 160 & 1.0 \\
\hline
\end{tabular}


Table 4. Dietary supplement use among the participants

(Number of participants and percentages)

\begin{tabular}{|c|c|c|c|c|c|c|}
\hline & \multicolumn{2}{|c|}{ All } & \multicolumn{2}{|c|}{ Men } & \multicolumn{2}{|c|}{ Women } \\
\hline & $n$ & $\%$ & $n$ & $\%$ & $n$ & $\%$ \\
\hline \multicolumn{7}{|l|}{ Any dietary supplements } \\
\hline Dietary supplement users & 39099 & $71 \cdot 2$ & 16572 & $63 \cdot 3$ & 22527 & $78 \cdot 3$ \\
\hline Non-supplement users & 15849 & $28 \cdot 8$ & 9609 & $36 \cdot 7$ & 6240 & $21 \cdot 7$ \\
\hline \multicolumn{7}{|l|}{ Types of dietary supplements used among supplement users } \\
\hline Multivitamin & 24880 & 63.6 & 10753 & 64.9 & 14127 & $62 \cdot 7$ \\
\hline Multimineral & 1362 & 3.5 & 439 & $2 \cdot 7$ & 923 & $4 \cdot 1$ \\
\hline Antioxidant & 14923 & $38 \cdot 2$ & 5987 & $36 \cdot 1$ & 8936 & 39.7 \\
\hline Vitamin B & 4579 & 11.7 & 1545 & $9 \cdot 3$ & 3034 & 13.5 \\
\hline $\mathrm{Ca}$ & 4320 & $11 \cdot 0$ & 462 & $2 \cdot 8$ & 3858 & $17 \cdot 1$ \\
\hline $\mathrm{Fe}$ & 1085 & $2 \cdot 8$ & 313 & 1.9 & 772 & 3.4 \\
\hline Fish oil & 9456 & $24 \cdot 2$ & 4301 & $26 \cdot 0$ & 5155 & 22.9 \\
\hline Vitamin D & 36 & 0.1 & 8 & 0.05 & 28 & 0.1 \\
\hline Other minerals (e.g. $\mathrm{Zn}, \mathrm{Mg}$ and $\mathrm{Cu}$ ) & 1349 & 3.5 & 289 & 1.7 & 1060 & 4.7 \\
\hline Ginseng & 3780 & $9 \cdot 7$ & 1629 & $9 \cdot 8$ & 2151 & $9 \cdot 6$ \\
\hline Gingko biloba & 1281 & $3 \cdot 3$ & 447 & $2 \cdot 7$ & 834 & 3.7 \\
\hline Garlic & 975 & 2.5 & 405 & $2 \cdot 4$ & 570 & 2.5 \\
\hline Royal jelly & 1098 & $2 \cdot 8$ & 88 & 0.5 & 1010 & 4.5 \\
\hline Wheat germ & 2631 & $6 \cdot 7$ & 1119 & $6 \cdot 8$ & 1512 & 6.7 \\
\hline Other alternatives (e.g. gut regulating, brewer's yeast and angelica) & 3206 & $8 \cdot 2$ & 905 & $5 \cdot 5$ & 2301 & $10 \cdot 2$ \\
\hline
\end{tabular}

common and less common dietary supplements (Table 5), as well as for all subgroups of supplements, except for fish oil, which was only borderline significantly more consumed among women, compared with men (OR 1.05, 95\% CI 1.00,
$1 \cdot 10)$. Older age ( $\geq 55$ years) was positively associated with the use of any, more common and less common dietary supplements (Table 5), as well as with multivitamin, multimineral, $\mathrm{Ca}$, fish oil, vitamin $\mathrm{B}$, antioxidant, gingko biloba, garlic and

Table 5. Associations between supplement use and demographic characteristics, health index and metabolic risk index

(Adjusted odds ratios and $95 \%$ confidence intervals)

\begin{tabular}{|c|c|c|c|c|c|c|}
\hline & \multicolumn{2}{|c|}{ Any dietary supplements } & \multicolumn{2}{|c|}{ More common supplements } & \multicolumn{2}{|c|}{ Less common supplements } \\
\hline & Adjusted OR* & $95 \% \mathrm{Cl}$ & Adjusted OR* & $95 \% \mathrm{Cl}$ & Adjusted OR* & $95 \% \mathrm{Cl}$ \\
\hline \multicolumn{7}{|l|}{ Sex } \\
\hline Male & 1.00 & Ref & 1.00 & Ref & 1.00 & Ref \\
\hline Female & 1.95 & $1 \cdot 88,2 \cdot 03$ & $1 \cdot 68$ & $1.62,1.74$ & 1.68 & $1.61,1.76$ \\
\hline \multicolumn{7}{|l|}{ Age (years) } \\
\hline $50-54$ & 1.00 & Ref & 1.00 & Ref & 1.00 & Ref \\
\hline $55-59$ & $1 \cdot 29$ & $1 \cdot 24,1 \cdot 35$ & $1 \cdot 27$ & $1 \cdot 22,1 \cdot 32$ & 1.08 & $1 \cdot 03,1.14$ \\
\hline $60-64$ & $1 \cdot 50$ & $1.43,1.58$ & 1.43 & $1.37,1.50$ & $1 \cdot 10$ & $1 \cdot 04,1 \cdot 16$ \\
\hline$P_{\text {trend }}$ & \multicolumn{2}{|c|}{$<0.0001$} & \multicolumn{2}{|c|}{$<0.0001$} & & \\
\hline \multicolumn{7}{|l|}{ Education } \\
\hline Low & 1.00 & Ref & 1.00 & Ref & 1.00 & Ref \\
\hline Middle & $1 \cdot 32$ & $1 \cdot 27,1 \cdot 38$ & $1 \cdot 30$ & $1 \cdot 25,1 \cdot 36$ & $1 \cdot 11$ & $1 \cdot 06,1 \cdot 17$ \\
\hline High & 1.54 & $1.46,1.63$ & 1.56 & $1.48,1.64$ & 1.02 & $0.96,1.09$ \\
\hline$P_{\text {trend }}$ & \multicolumn{2}{|c|}{$<0.0001$} & \multicolumn{2}{|c|}{$<0.0001$} & \multirow{2}{*}{\multicolumn{2}{|c|}{$0 \cdot 11$}} \\
\hline \multicolumn{5}{|l|}{ Health index } & & \\
\hline 0 & 1.00 & Ref & 1.00 & Ref & 1.00 & Ref \\
\hline 1 & $1 \cdot 17$ & $1 \cdot 05,1 \cdot 30$ & $1 \cdot 16$ & $1 \cdot 04,1 \cdot 28$ & $1 \cdot 16$ & $1.00,1.34$ \\
\hline 2 & 1.49 & $1 \cdot 35,1.65$ & $1 \cdot 40$ & $1 \cdot 27,1.55$ & 1.35 & $1.18,1.55$ \\
\hline 3 & 1.75 & $1.58,1.93$ & $1 \cdot 62$ & $1.47,1.78$ & 1.43 & $1 \cdot 25,1.64$ \\
\hline 4 & 1.99 & $1 \cdot 79,2 \cdot 22$ & $1 \cdot 82$ & $1 \cdot 64,2.02$ & 1.49 & $1 \cdot 29,1 \cdot 71$ \\
\hline$P_{\text {trend }}$ & \multicolumn{2}{|c|}{$<0.0001$} & \multicolumn{2}{|c|}{$<0.0001$} & \multicolumn{2}{|c|}{$<0.0001$} \\
\hline Per score increment & $1 \cdot 19$ & $1 \cdot 17,1 \cdot 22$ & $1 \cdot 16$ & $1 \cdot 14,1 \cdot 19$ & 1.09 & $1.06,1.11$ \\
\hline \multicolumn{7}{|l|}{ Metabolic risk index } \\
\hline 0 & 1.00 & Ref & $1 \cdot 00$ & Ref & 1.00 & Ref \\
\hline 1 & 0.90 & $0.85,0.95$ & 0.88 & $0.85,0.92$ & 1.03 & $0.98,1.08$ \\
\hline 2 & 0.72 & $0.67,0.78$ & 0.70 & $0.66,0.74$ & 1.02 & $0.96,1.09$ \\
\hline 3 & 0.56 & $0.43,0.72$ & 0.56 & $0.45,0.69$ & 0.90 & $0.67,1.20$ \\
\hline$P_{\text {trend }}$ & \multicolumn{2}{|c|}{$<0.0001$} & \multicolumn{2}{|c|}{$<0.0001$} & \multicolumn{2}{|c|}{0.3875} \\
\hline Per score increment & 0.83 & $0.81,0.85$ & 0.84 & $0.82,0.86$ & 1.01 & $0.98,1.04$ \\
\hline
\end{tabular}

Ref, reference.

${ }^{*}$ All covariates listed in the table were mutually adjusted. 
wheat germ. An inverse association had been found for Fe and royal jelly, while no association had been found for ginseng. Participants with long or median length of education were more likely to be users of any and more common supplements, as well as of gingko biloba, vitamin B, Ca, antioxidant, multivitamin, multimineral and Fe supplements. For less common supplements, only those in the middle group of education were more likely to be users, which had also been found for garlic and ginseng supplements. Participants with a high education were less likely to be users of wheat germ, fish oil and royal jelly supplements.

\section{Health index}

A 1-point higher score in the health index has been positively associated with the use of any supplement (OR 1·19, 95\% CI $1 \cdot 17,1 \cdot 22$ ), more common supplements (OR 1.16, 95\% CI $1 \cdot 14,1 \cdot 19)$ and less common supplements (OR 1.09, 95\% CI 1.06, 1.11). Participants who achieved the maximum score in the health index had an OR for supplement use of 1.99 (95\% CI 1.79, 2.22), 1.82 (95\% CI 1.64, 2.02) and 1.49 (95\% CI $1.29,1.79)$ for any dietary supplements, more common supplements and less common supplements, respectively, compared with those achieving the minimum score (Table 5). In all the analyses, strong trends were found $(P<0.0001)$. Similar results were found for the use of Fe, multivitamin, multimineral, antioxidant, $\mathrm{Ca}$, gingko biloba, wheat germ and fish oil supplements, but not for royal jelly, garlic and ginseng supplements (data not shown).

\section{Metabolic risk index}

A 1-point higher score was negatively associated with the use of any supplement (OR 0.83, 95\% CI 0.81, 0.85) and more common supplements (OR 0.84, 95\% CI 0.82, 0.86); however, no significant association for less common supplements was found (OR 1.01, 95\% CI 0.98, 1.04). Participants with the maximum score were less likely to be users of any (OR 0.56 , $95 \%$ CI $0.43,0.72$ ) and more common supplements (OR 0.56, $95 \%$ CI $0.45,0.69)$. This was consistent with the findings for $\mathrm{Ca}$, antioxidant, multivitamin and vitamin $\mathrm{B}$ supplements. For less common supplements, no difference was found between the highest and the lowest scores (OR 0.90, 95\% CI $0 \cdot 67,1 \cdot 20$ ), which has also been consistent with the results for ginseng, garlic, royal jelly, Fe, multimineral, gingko biloba, fish oil and wheat germ supplements (data not shown).

\section{Discussion}

In this large cross-sectional study of middle-aged men and women, aged 50-64 years, where $71 \%$ of the participants were users of dietary supplements, female sex, older age groups and higher educated participants were more likely to be users of any dietary supplements. One additional point in the health index has been associated with 19, 16 and 9\% higher likelihood of being user of any, more common and less common supplements, respectively. In the metabolic risk index, one additional point has been associated with $17 \%$ and
$16 \%$ lower likelihood of being user of any supplement and more common supplements, respectively. No significant association has been found for less common supplement use.

\section{Demographics and health index}

Our finding that women and older subjects are more likely to use dietary supplements is supported by other studies $(1,3,4,6,11,18,19)$. Similarly, our findings that a higher educational level has been associated with the use of dietary supplements is consistent with previous studies ${ }^{(1,2,4-7,19-24)}$. In the present study, higher adherence to the health index was associated with dietary supplement use. No other studies have combined the determinants in the same way, and we thus conducted a supplementary analysis investigating the factors of the health and metabolic indices separately, in order to be able to compare the present results with the existing studies (online Supplementary Table s1): Physical activity has been found to be significantly associated with dietary supplement use; however, in the present study, the association was only borderline significant (any supplement: OR 1.04, 95\% CI 0.99, 1.08). Previous findings have shown that former smokers were more likely to be supplement users and current smokers were less likely to be dietary supplement users, compared with never smokers $^{(3,7,8,19,20,25,26)}$. This was also the case in the present study, both when considering any dietary supplement, as well as more and less common supplements separately (online Supplementary Table s1). In the present study, alcohol intake below the recommendations was significantly associated with any and common supplement use, but we did not investigate the types of alcohol separately. Two studies ${ }^{(23,27)}$ that investigated the type of alcohol have found positive associations for wine consumption, but no associations for beer consumption. This could indicate that the type of alcohol should also be taken into account when investigating alcohol and dietary supplement use. The differences in supplement use between beer and wine intake might be explained by some other factors. It has been found that subjects who bought wine were also likely to buy fruit, vegetables, poultry and cereals ${ }^{(28)}$. This is supported in the present study population, since it has previously been found that higher intake of fruit, fish and vegetables has been associated with drinking wine ${ }^{(29)}$. Thus, wine drinkers could have higher health awareness or higher social class.

In addition, three studies have investigated intentions and knowledge about healthy diet among supplement users. One study ${ }^{(11)}$ has found that the use of dietary supplements increased with the intention to eat in a healthy way, and another study ${ }^{(30)}$ has reported that the personal importance of consuming a diet consistent with dietary recommendations is a significant predictor of supplement use. A third study has found supplement users to have increased familiarity with official nutritional recommendations ${ }^{(1)}$.

\section{Metabolic index}

We included waist circumference rather than BMI in the metabolic index, as an indicator of overweight, as this is used when 
defining the metabolic syndrome ${ }^{(31)}$, and as waist circumference has been shown to be a better predictor of adiposity in middle-aged individuals due to the redistribution of excess fat centrally with increasing age ${ }^{(32)}$. Previous studies have mostly investigated BMI as a determinant for supplement use. Most studies have found that overweight/obese individuals are less likely to use supplements ${ }^{(1,2,6,9,19,20,23,25,26,33)}$, consistent with our findings for any and common dietary supplement use (online Supplementary Table s1). In one study, waist circumference has been investigated, providing results also consistent with ours ${ }^{(34)}$. Urine glucose, an indicator for lack of glucose homeostasis, was included in the metabolic risk index as a proxy for diabetes risk. Information about self-reported diabetes was collected, but not validated, and therefore not included in the present study. Previous findings for diabetes and use of dietary supplements are inconsistent, some reporting an inverse association $^{(3,26)}$, while others report no association ${ }^{(9,20,21)}$.

\section{The index approach}

The use of an index approach to determinants of dietary supplement use in the present study is novel, and allows investigation of a lifestyle pattern, rather than merely individual lifestyle factors.

The results support the findings of previous studies; showing that dietary supplement users are generally more health-conscious than non-users ${ }^{(1-3)}$ : We found a strong trend across both indices for any and common supplement use, and for the health index also alternative supplement use (Table 5). The advantages of using an index approach thus includes that it presents a simple and intuitive understanding of the association between lifestyle/health and dietary supplement use; a similar association was found in the supplementary analyses and in previous studies examining individual components, but the public health communication of these results becomes more complex than when using an index approach. Furthermore, this study forms a relevant basis for investigation of confounding in studies on supplement use and health outcomes, and as multiple lifestyle factors often interact, resulting in a multi-causal nature of disease, the use of indices as confounder control in future studies may be highly relevant. For example, the health index used in this study has previously been found strongly related to mortality in the same cohort ${ }^{(17)}$. Inclusion of indices in future studies also has the advantage of upholding statistical power compared to inclusion of several individual variables. This may especially be of relevance when investigating the use of less common supplements. At present, the use of novel indices hampers comparison with previous studies; however, with the growing tendency towards health indices $^{(17)}$, it may in the future facilitate comparison.

If the metabolic risk index is seen as an 'unhealthy index', it could be argued that the results from the health index and metabolic risk index are consistent (since the two indexes are inversely correlated). A higher score in the health index had been associated with the use of any dietary supplement, while a higher score in the metabolic risk index had been associated with a lower use. Thus, the results between these two indexes are concordant.

\section{Strengths and limitations}

The strengths of the present study include a large sample size, which gives the opportunity to examine the determinants for several different dietary supplements. Several limitations of the present study should, however, be mentioned: The questions in the FFQ regarding supplement use are not validated. It has previously been found that dietary supplement use is measured quite well in self-administered questionnaires ${ }^{(35)}$, which increases the validity of the present study. There could probably be some misclassification in the present study, if not all participants had reported all types of supplements used in the past year. The participants should report the use of supplements during the past year, which is a relatively long period. For some, it could be hard to remember exactly when and which type of supplement they had used, if the use was not regular.

A standardised definition of dietary supplement use does not exist; thus, previous studies have defined dietary supplement use in many different ways that may explain some inconsistencies between the studies. In the present study, dietary supplement users were defined as subjects who had taken at least one supplement during the past year, and this definition was also applied in some other studies $^{(1,19,24)}$. Some studies have used more strict definitions where dietary supplement users were defined as subjects who had taken supplements during the past week ${ }^{(21)}$ or who used supplements on a regular basis, such as every day or week ${ }^{(7)}$. Thus, an explanation for the high prevalence of supplement use in the present study may partly be explained by the definition of the users.

From the FFQ and lifestyle questionnaires, as well as the literature, information about potential confounders was gathered. In the present study, adjustment for the included determinants was performed. We did not observe noteworthy differences between crude and adjusted estimates. Residual confounding may still occur, although adjustments were performed. A factor such as income might be a potential confounder, since other studies have adjusted for this variable ${ }^{(5,7,19)}$. Income was not available in the study, which might be a limitation.

The age range of the study population was limited to 50-64 years. It gives a more homogenous study population; however, it impairs the opportunity of generalisation to a broader age range. Furthermore, only 34 and $37 \%$ of the invited men and women, respectively, participated in the cohort study ${ }^{(14)}$, and participants had a higher socio-economic position than non-participants. Previous findings have shown that subjects with a higher socio-economic position tend to follow the national recommendations for a healthy diet to a higher degree, whereas those with a lower socio-economic position are more likely to smoke ${ }^{(36,37)}$. This will affect the generalisability, since it might appear that the participants are healthier than non-participants. Furthermore, it is important to mention that the participants were living in the bigger cities of 
Copenhagen and Aarhus ${ }^{(14)}$. This urban population may differ from the rural population, or might be related to socioeconomic status.

\section{Conclusion}

In conclusion, the results of the present study showed that $71 \%$ of the cohort participants were dietary supplement users. Female sex, older age and higher educational level were determinants of dietary supplement use. In addition, those with the healthiest lifestyle were more likely to use dietary supplements. These findings support the previous findings that supplement users are generally more healthconscious, also in this population with a high prevalence of supplement use. Thus, lifestyle and dietary composition should be considered as confounders in studies on supplement use and health outcomes.

\section{Supplementary material}

To view supplementary material for this article, please visit http://dx.doi.org/10.1017/S0007114515001440

\section{Acknowledgements}

The authors acknowledge Katja Boll, data manager, and Nick Martinussen, data manager, for assistance with the data collection and handling.

The present study was supported by the Danish Cancer Society.

None of the authors has any conflicts of interest to declare.

The authors' contributions are as follows: C. L. F. K. analysed the data and J. C. provided statistical expertise; C. L. F. K. drafted the manuscript under the supervision of A. T., J. C., L. O. D., and N. R.; N. R. revised the manuscript after review comments; C. L. F. K., A. T., N. R. and L. O. D. discussed the design and scope of the study, approved the results and critically commented on the manuscript. All authors read and approved the manuscript.

\section{References}

1. Pouchieu C, Andreeva VA, Peneau S, et al. (2013) Sociodemographic, lifestyle and dietary correlates of dietary supplement use in a large sample of French adults: results from the NutriNet-Sante cohort study. Br J Nutr 110, $1480-1491$.

2. Foote JA, Murphy SP, Wilkens LR, et al. (2003) Factors associated with dietary supplement use among healthy adults of five ethnicities: the Multiethnic Cohort Study. Am J Epidemiol 157, 888-897.

3. Harrison RA, Holt D, Pattison DJ, et al. (2004) Are those in need taking dietary supplements? A survey of 21923 adults. Br J Nutr 91, 617-623.

4. Reinert A, Rohrmann S, Becker N, et al. (2007) Lifestyle and diet in people using dietary supplements: a German cohort study. Eur J Nutr 46, 165-173.

5. Guo X, Willows N, Kuhle S, et al. (2009) Use of vitamin and mineral supplements among Canadian adults. Can J Public Health 100, 357-360.
6. Marques-Vidal P, Pecoud A, Hayoz D, et al. (2009) Prevalence and characteristics of vitamin or dietary supplement users in Lausanne, Switzerland: the CoLaus study. Eur J Clin Nutr 63, 273-281.

7. Peklar J, Henman MC, Richardson K, et al. (2013) Food supplement use in the community dwelling population aged 50 and over in the Republic of Ireland. Complement Ther Med 21, 333-341.

8. Touvier M, Niravong M, Volatier JL, et al. (2009) Dietary patterns associated with vitamin/mineral supplement use and smoking among women of the E3N-EPIC cohort. Eur J Clin Nutr 63, 39-47.

9. Gu F, Schumacher FR, Canzian F, et al. (2010) Eighteen Insulin-like Growth Factor (IGF) pathway genes, circulating levels of IGF-1 and its binding protein (IGFBP-3), and risk of prostate and breast cancer. Cancer Epidemiol Biomarkers Prev 19, 2877-2887.

10. Hutchinson J, Burley VJ, Greenwood DC, et al. (2011) High-dose vitamin C supplement use is associated with self-reported histories of breast cancer and other illnesses in the UK Women's Cohort Study. Public Health Nutr 14, $768-777$

11. Tetens I, Biltoft-Jensen A, Spagner C, et al. (2011) Intake of micronutrients among Danish adult users and non-users of dietary supplements. Food Nutr Res $\mathbf{5 5}$ (epublication 7 September 2011).

12. Knudsen VK, Rasmussen LB, Haraldsdottir J, et al. (2002) Use of dietary supplements in Denmark is associated with health and former smoking. Public Health Nutr 5, 463-468.

13. Skeie G, Braaten T, Hjartåker A, et al. (2009) Use of dietary supplements in the European Prospective Investigation into Cancer and Nutrition calibration study. Eur J Clin Nutr 63, S226-S238.

14. Tjønneland A, Olsen A, Boll K, et al. (2007) Study design, exposure variables, and socioeconomic determinants of participation in Diet, Cancer and Health: a population-based prospective cohort study of 57,053 men and women in Denmark. Scand J Public Health 35, 432-441.

15. Overvad K, Tjonneland A, Haraldsdottir J, et al. (1991) Development of a semiquantitative food frequency questionnaire to assess food, energy and nutrient intake in Denmark. Int J Epidemiol 20, 900-905.

16. Lauritsen J (1998) Computer Program: Foodcalc Version 1.3. Copenhagen: Diet, Cancer and Health Cohort. http:// www.foodcalc.dk (accessed 25 March 2010).

17. Petersen KE, Johnsen NF, Olsen A, et al. (2015) The combined impact of adherence to five lifestyle factors on all-cause, cancer and cardiovascular mortality: a prospective cohort study among Danish men and women. Br J Nutr $\mathbf{1 1 3}$, $849-858$

18. de Jong N, Ocké MC, Branderhorst HA, et al. (2003) Demographic and lifestyle characteristics of functional food consumers and dietary supplement users. BrJ Nutr 89, 273-281.

19. Fennell D (2004) Determinants of supplement usage. Preven Med 39, 932-939.

20. Lyle BJ, Mares-Perlman JA, Klein BE, et al. (1998) Supplement users differ from nonusers in demographic, lifestyle, dietary and health characteristics. J Nutr 128, 2355-2362.

21. Wallström P, Elmstahl S, Hanson BS, et al. (1996) Demographic and psychosocial characteristics of middle-aged women and men who use dietary supplements. Results from the Malmo Diet and Cancer Study. Eur J Public Health 6, 188-195.

22. Schaffer DM, Gordon NP, Jensen CD, et al. (2003) Nonvitamin, nonmineral supplement use over a 12 -month period by adult members of a large health maintenance organization. $J \mathrm{Am}$ Diet Assoc 103, 1500-1505. 
23. Radimer K, Bindewald B, Hughes J, et al. (2004) Dietary supplement use by US adults: data from the National Health and Nutrition Examination Survey, 1999-2000. Am J Epidemiol 160, 339-349.

24. Yu SM, Kogan MD \& Huang ZJ (2002) Vitamin-mineral supplement use among US women, 2000. J Am Med Womens Assoc 58, 157-164.

25. Kirk SF, Cade JE, Barrett JH, et al. (1999) Diet and lifestyle characteristics associated with dietary supplement use in women. Public Health Nutr 2, 69-73.

26. Hoggatt KJ, Bernstein L, Reynolds P, et al. (2002) Correlates of vitamin supplement use in the United States: data from the California Teachers Study cohort. Cancer Causes Control 13, 735-740.

27. Beitz R, Mensink GB, Hintzpeter B, et al. (2004) Do users of dietary supplements differ from nonusers in their food consumption? Eur J Epidemiol 19, 335-341.

28. Johansen D, Friis K, Skovenborg E, et al. (2006) Food buying habits of people who buy wine or beer: cross sectional study. BMJ 332, 519-522.

29. Tjonneland A, Gronbaek M, Stripp C, et al. (1999) Wine intake and diet in a random sample of 48763 Danish men and women. Am J Clin Nutr 69, 49-54.

30. Sebastian RS, Cleveland LE, Goldman JD, et al. (2007) Older adults who use vitamin/mineral supplements differ from nonusers in nutrient intake adequacy and dietary attitudes. J Am Diet Assoc 107, 1322-1332.
31. Zimmet P, Magliano D, Matsuzawa Y, et al. (2005) The metabolic syndrome: a global public health problem and a new definition. $J$ Atheroscler Thromb 12, 295-300.

32. World Health Organization (2000) Obesity: Preventing and Managing the Global Epidemic. Report of a WHO Consultation. World Health Organisation Technical Report Series no. 894. Geneva: WHO pp. 1-253.

33. Gunther S, Patterson RE, Kristal AR, et al. (2004) Demographic and health-related correlates of herbal and specialty supplement use. J Am Diet Assoc 104, 27-34.

34. McNaughton SA, Mishra GD, Paul AA, et al. (2005) Supplement use is associated with health status and healthrelated behaviors in the 1946 British birth cohort. J Nutr 135, 1782-1789.

35. Messerer M \& Wolk A (2004) Sensitivity and specificity of self-reported use of dietary supplements. Eur J Clin Nutr 58, 1669-1671.

36. Groth MV \& Fagt S (2003) Danskernes kostvaner Måltidsvaner, holdninger, sociale forskelle og sammenhaeng med anden livsstil (Danish Dietary Habits - Meal Habits, Attitudes, Social Differences and Relationship with Other Lifestyle). Søborg: Ministeriet for Fødevarer, Landbrug og Fiskeri.

37. Kjøller M, Juel K \& Kamper-Jørgensen F (2007) Folkesundhedsrapporten, Danmark 2007 (The Public Health Report, Denmark 2007). Copenhagen: Statens Institut for Folkesundhed. 